\title{
Militância e liberdade: a relação entre Marighella e o cristianismo de libertação
}

\author{
Militancy and freedom: The relationship between \\ Marighella and liberation Christianity
}

\section{Militancia y libertad: la relación entre Marighella y el cristianismo de liberación}

\author{
Luis Fernando de Carvalho Sousa*
}

\begin{abstract}
RESUMO
Esse artigo tem como intuito tratar da relação entre o Carlos Marighella e o cristianismo de libertação, buscando fazer a aproximação entre os horizontes que fazem dessas duas perspectivas, embora aparentemente antagônicas, congruentes na luta por liberdade e democracia. Ambos os movimentos são datados da década de 1960, quando o Brasil sofreu a interrupção de sua democracia por um golpe civil-militar efetuado por matrizes conservadoras que impuseram ao país vinte anos de um sistema violento e cerceador de liberdade. Com isso uma das poucas opções que restaram foi também a resistência violenta através da luta armada.

Palavras-chave: cristianismo de libertação; Marighella; liberdade; militância.
\end{abstract}

\begin{abstract}
This article intends to deal with the relationship between Carlos Marighella and liberation Christianity, seeking to bring the horizons that make these two perspectives, although apparently antagonistic, congruent in the struggle for freedom and democracy. Both movements date from the 1960s, when Brazil suffered the interruption of its democracy by a civil-military coup carried out by conservative matrons who imposed on the country twenty years of a violent system and liberator. With that one of the few options that remained was also the violent resistance through the armed struggle

Keywords: Christianity of liberation; Marighella; freedom; militancy.
\end{abstract}

\section{RESUMEN}

Este artículo tiene como objetivo abordar la relación entre Carlos Marighella y el cristianismo de la liberación, buscando acercar los horizontes que hacen que estas dos perspectivas, aunque aparentemente antagónicas, sean congruentes en la lucha por la libertad y la democracia. Ambos movimientos datan de la década de 1960, cuando Brasil sufrió la interrupción de su democracia por un golpe cívico-militar llevado a cabo por matrices conservadoras que impusieron veinte años de un sistema violento y restrictivo de la libertad en el país. Con eso, una de las pocas opciones que quedaba era también la resistencia violenta a través de la lucha armada.

Palabras clave: cristianismo de liberación; Marighella; libertad; militancia.

Licenciado em história (UBM), bacharel em teologia (Umesp) e mestre em filosofia (UNIOESTE). 


\section{Origem histórica do cristianismo de libertação}

Esse artigo tem por objetivo analisar o papel da religião - em particular o movimento conhecido como cristianismo de libertação ${ }^{1}$ como resistência política, sobretudo, pela relação de religiosos cristãos com Carlos Marighella, líder da Aliança Libertadora Nacional (ALN) e "inimigo número um da ditadura militar" (JOSÉ, 2004).

Dessa forma, investigará a relação da práxis cristã libertária com a práxis marxista adotada pela ALN, visando apontar as congruências e dissonâncias de seus respectivos "horizontes utópicos". 2

Tratar do cristianismo de libertação constitui-se num grande desafio. $\mathrm{O}$ assunto já foi abordado exaustivamente nas produções que se fez sobre o tema, sobretudo, durante a década de 1980. Datam desse período as produções mais concisas e completas sobre tema. Os anos de 1980 foram talvez os mais significativos para a Teologia da Libertação por conta da advertência publicada pelo Vaticano. Como destaca Cláudio de Oliveira Ribeiro “[...] os anos 1980 foram marcados pela polêmica em relação à Instrução sobre alguns aspectos da Teologia da Libertação, publicada pelo Vaticano" (RIBEIRO, 2010, p. 23). Também essa década pode ser considerada o auge da produção teórica sobre o tema.

O cristianismo de libertação é fruto de um movimento. Como tal torna-se difícil uma datação de seu surgimento. Seus estudiosos, quase em sua totalidade, a consideram como uma teologia da práxis que teve sua sistematização posterior a seu surgimento. Nas décadas de 1950 e 1960 a América Latina vivia uma efervescência política e, com isso, alguns grupos foram se organizando com o intuito de interagir socialmente na proposta de mudanças estruturais na sociedade.

Michel Löwy é um dos estudiosos sobre o tema. Para ele, os acontecimentos que dão origem ao movimento iniciaram de maneira espontânea no seio da sociedade, por isso prefere não denominar a corrente como teologia da libertação. Löwy prefere o termo cristianismo de libertação, por ser um movimento e uma corrente que, desde seu início, extrapolou as fronteiras da igreja e os círculos acadêmicos. Sem dúvidas, isso se deve à

Essa nomenclatura é utilizada por teóricos como (LÖWY, 2000) que concebe o cristianismo de libertação como um movimento que congrega leigos e clérigos e não se restringe somente ao campo teológico, mas é marcado pela militância política inspirada em valores cristãos. Por isso a utilização do termo cristianismo de libertação e não teologia da libertação como é comumente mencionado.

2 Por horizonte utópico entendemos o marco transcendente que norteia as ações e práticas ideárias de distintos grupos sociais. Ver: HINKELAMMERT, Franz J. Critica a la razón utopica. San José: DEI, 1984, p. 15. 
sua formação e olhar sociológico, entretanto, dentro da proposta teológica a teologia deve dialogar com todas as áreas da sociedade, não se restringindo, por exemplo, à igreja, mas como Löwy faz abordagem sociológica entendemos e respeitamos sua posição que é assim definida:

\begin{abstract}
Proponho chamá-lo de cristianismo de libertação, por ser esse um conceito mais amplo que "teologia" ou que "igreja" e incluir tanto a cultura religiosa e a rede social, quanto a fé e a prática. Dizer que se trata de um movimento social não significa necessariamente dizer que ele é um órgão "integrado" e "bem coordenado", mas apenas que tem, como outrora movimentos semelhantes (feminismo, ecologia, etc.), uma certa capacidade de mobilizar as pessoas ao redor de objetivos comuns (LÖWY, 2000, p. 27).
\end{abstract}

Embora faça essa análise sociológica, com a qual concordamos em parte, o sociólogo não deixa de reconhecer que a práxis do movimento ligase diretamente à sua produção teórica estabelecendo uma relação dialética entre práxis e teoria como assenta nessa afirmativa: “[...] ao mesmo tempo a teologia da libertação é, ao mesmo tempo, reflexo de uma práxis anterior e um reflexo sobre essa práxis" (LÖWY, 2000, p. 56). É um movimento e uma produção teórica que influenciou uma geração de pessoas no continente latino-americano e que servia, ao mesmo tempo, como resistência ao modelo desenvolvimentista que era proposto. Por isso o cristianismo de libertação foi duramente combatido e perseguido; ele destoava da ordem mundial proposta pelas potências capitalistas.

Enrique Dussel destaca alguns eventos com fundo histórico e que foram de suma importância para o desenvolvimento da corrente libertária. Esse autor analisa a corrente de forma diferente dos demais movimentos. Ele faz uma interpretação simbólica do surgimento do cristianismo de libertação mencionando que seu precursor seria Bartolomeu da las Casas, quando produziu um pensamento de resistência ao império espanhol em fins do século XV e início do século XVI. Dussel se empenha em fazer um histórico de movimentos teológicos anti-hegemônicos desde a conquista da América Latina até o século XX. No que a maioria dos teólogos e historiadores denomina de surgimento da corrente, Dussel faz a seguinte constatação:

Desde 1959 - com o anúncio do Concílio Vaticano II e a ocupação de Havana pelas forças revolucionárias de Fidel Castro e do Che Guevara - foi sendo gerada lentamente uma nova situação teológica. A crise da Ação Católica e daí a importância da obra de José Comblin (nasceu em 1923) sobre o Fracasso da Ação Católica (1961) - é um fruto do colapso do "populismo”. A derrubada em 1954 de Arbenz na Guatemala (pelo golpe de Castillo Armas preparado pela CIA) e de Vargas no Brasil (que se suicidou por não poder resistir mais à pressão do embaixador norte-americano), em 1955 o fim do 
governo peronista na Argentina, em 1957 o de Pérez Giménez na Venezuela e o de Rojas Pinilla na Colômbia, em 1959 o de Fulgêncio Batista em Cuba, como indicamos acima, abrem à hegemonia indiscutível dos Estados Unidos na América Latina. É a década do "desenvolvimento" que ocupará lugar da Ação Católica (DUSSEL, 1999, p. 51-52).

Dussel ainda destaca que a produção teológica e mudança de alguns paradigmas no seio das igrejas devia-se também à forte inserção da juventude em meios políticos e sociais. Como uma das correntes que estimulou essa inserção, o estudioso destacou a Ação Católica.

A Ação Católica notabilizou-se por utilizar o método ver-julgar-agir e no Brasil foi precursora no movimento libertário no seio do catolicismo. Löwy destaca que no ano de 1962 movimentos pastorais leigos da Igreja Católica criaram, inspirados no ideal de libertação, a Ação Popular (AP) "[...] movimento não-confessional dedicado à luta pelo socialismo e ao uso do método marxista" (LÖWY, 2000, p. 139). Um dos integrantes desse movimento era Herbert de Souza, o Betinho, que se notabilizou nos anos 1990 por sua luta contra a fome e pobreza no Brasil através de programas sociais.

Löwy faz uma extensa análise do desenvolvimento da corrente no continente latino-americano em A Guerra dos deuses: religião e política na América Latina (2000). Contudo, o resumo dos eixos principais tratados pelo cristianismo de libertação que faz em sua obra chamam a atenção e merecem ser reproduzidos, pois sintetizam, sem dúvida, os principais objetivos e pressupostos da corrente.

1. A luta contra a idolatria (não o ateísmo) como inimigo principal da religião, isto é, contra os novos ídolos da morte adorados pelos novos Faraós, pelos novos Césares e pelos novos Herodes: Bens materiais, Riqueza, o Mercado, a Segurança Nacional, o Estado, a Força Militar, a "Civilização Ocidental Cristã".

2. Libertação humana na história como antecipação doa salvação final em Cristo,o Reino de Deus.

3. Uma crítica da teologia dualista tradicional, como produto de filosofia grega de Platão, e não da tradição bíblica na qual a história humana e a história divina são diferentes, mas inseparáveis.

4. Uma nova leitura da Bíblia, que dá uma atenção significativa a passagens tais como o Êxodo, que é vista como paradigma de uma luta de um povo escravizado por sua libertação.

5. Uma forte crítica moral e social ao capitalismo dependente como sistema injusto e iníquo, como uma forma de pecado estrutural.

6. O uso do marxismo como instrumental sócio analítico a fim de entender as causas da pobreza, as contradições do capitalismo e as formas de luta de classes.

7. A opção preferencial pelos pobres e a solidariedade com sua luta pela autolibertação.

8. O desenvolvimento de comunidades de base cristãs entre os pobres como uma nova forma de Igreja como alternativa para o modo de vida individualista imposto pelo sistema capitalista (LÖWY, 2000, p. 61). 
Como temos afirmado não há consenso de uma data precisa do surgimento da corrente. As datações e afirmações feitas de forma inequívoca não encontram espaço quando dizem respeito ao surgimento dessa corrente teológica. O que se tem são eventos históricos, políticos e sociais que confluíram para sua formação e desenvolvimento. E nesse sentido, inegavelmente, o Concílio Vaticano II foi um dos suportes de grande importância que o catolicismo dispôs para empreender o processo de desenvolvimento de uma teologia mais arrojada e comprometida com as demandas do continente latino-americano.

O Concílio trazia a proposta de aggiornamento, ou seja, um avanço e adaptação dos pressupostos e doutrinas cristãs à realidade. Na América Latina tal proposta relacionava-se diretamente com a realidade das populações que viviam num continente subdesenvolvido, na periferia do capitalismo mundial e que necessitavam de maior interação da forma de ser igreja com sua realidade. Nesse sentido, a proposta de uma opção pelos pobres, descentralização eclesiológica através das Comunidades Eclesiais de Base (CEB's) e atuação de pastorais sociais coaduna com os anseios e efervescência que se vivia no continente. Ribeiro assim destaca a influência do Concílio Vaticano II no desenvolvimento do cristianismo de libertação:

[...] A Igreja Católica Romana motivada por mudanças ocasionadas pelo Concílio Ecumênico Vaticano II (1962-1965) e pela Conferência Episcopal Latino-Americana de Medelín (1968), experimentou uma nova eclesialidade a partir da formação e a da prática das Comunidades Eclesiais de Base (CEBs), com o apoio de setores de hierarquias firmados especialmente na “opção preferencial pelos pobres” (RIBEIRO, 2010, p. 28).

A articulação entre o movimento de libertação e a militância política da ALN é retratada em Batismo de Sangue (1982). O livro é uma obra de Frei Betto, que mistura diversos elementos: resenha histórica, depoimento e biografia, conduzida por um estilo ensaístico e romanesco. Embora não seja um típico romance, utiliza categorias do gênero. A obra ganhou relevância internacional por tornar público aspectos, tanto da clandestinidade, quanto do regime militar, além constituir-se em tentativa de sintetizar a relação de alguns dominicanos - adeptos do cristianismo de libertação - com o político e revolucionário, Carlos Marighella.

\section{Marighella e os dominicanos}

No ano de 1964, houve um conluio entre a burguesia nacional brasileira e setores conservadores das forças armadas, que acabaram por instaurar no 
país um regime militar de matriz conservadora (DREIFUSS, 1981). Mas foi, sobretudo, no ano de 1968, que o regime se recrudesceu, impondo uma série de sanções individuais e coletivas aos cidadãos brasileiros. Nos primórdios, não havia entre os militares um consenso sobre o modus operandi do novo regime. Para a linha representada por Castelo Branco, primeiro presidente eleito pelo Congresso Nacional sob os efeitos do Ato Institucional número 1 (AI-1), o regime militar seria temporário, com um rápido retorno à democracia, por outro lado, para a ala denominada "linha dura" o regime deveria estender-se (BORGES, 2007, p. 40). ${ }^{3}$

O grupo de cristãos libertários, ${ }^{4}$ que incluía os dominicanos, tinha posição política contrária à que vigorava no país, especialmente a partir de 1968, quando foi decretado o Ato Institucional número 5 (AI-5), que impôs uma série de sanções políticas ao Brasil. Por isso, dentro de suas possibilidades e de sua condição de religiosos, ajudavam pessoas que corriam risco de prisão e de tortura a serem recebidas em outras localidades - a exemplo de Igrejas em países europeus, como a Polônia, que abrigavam esses militantes (BETTO, 1982).

Alguns dominicanos (entre eles, Frei Betto) tinham uma opção política contrária à que vigorava no país, especialmente a partir de 1968, quando foi decretado o AI - 5 (Ato Institucional número 5), que impôs uma série de sanções políticas no Brasil. Por isso, dentro de suas possibilidades e de sua condição de religiosos, ajudavam pessoas que corriam risco de prisão e de tortura, a exemplo de algumas igrejas em alguns países europeus, como a Polônia (BETTO, 1982, p .48).

Frente à opressão e à supressão da liberdade imposta pelo regime, a via democrática não se mostrava eficaz (o Partido Comunista estava na ilegalidade) para que fosse buscada uma alternativa que pudesse fazer com que os cidadãos brasileiros pudessem gozar de maior liberdade, não sendo mais submetidos à exploração capitalista. Por esse motivo, a via revolucionária liderada por Marighella foi uma alternativa que os simpatizantes mais inconformados do comunismo encontraram para tentar derrubar a ditadura.

\footnotetext{
Cf. BORGES, Nilson. A Doutrina de Segurança Nacional e os Governos Militares. In: FERREIRA, Jorge; NEVES DELGADO, Lucilia de Almeida (orgs.). O tempo da ditadura: regime militar e movimentos sociais em fins do século XX. Rio de Janeiro: Civilização Brasileira, 2007. Nesse texto tem-se uma completa análise dessa questão enunciada. Tomamos sua expressão como exemplo apenas para introduzir o assunto, uma vez que, os conceitos e temática envolvidos demandam uma discussão mais ampla.

4 No seio da igreja católica havia grupos com uma posição mais à esquerda, no que tange ao campo político e ideológico, denominado cristãos libertários ou "esquerda católica”, dos quais se destacam os grupos pastorais (Juventude, Operária, Universitária etc.).
} 
Foi nesse contexto que Frei Betto conheceu Carlos Marighella, mais precisamente em maio de 1969 (BETTO, 1982, p. 56). O líder da ALN pediu ajuda ao frei, que estava de viagem para o sul do país, na passagem de militantes vivendo sob a clandestinidade para o Uruguai. Inicialmente o apoio se deu por meio da ajuda aos militantes e, posteriormente, os religiosos resolveram integrar o grupo revolucionário de Marighella.

A trajetória política de Carlos Marighella apesar de extensa e conturbada, pode ser resumida em alguns parágrafos. O político nasceu em Salvador no ano de 1911 e ingressou no Partido Comunista do Brasil (PCB), em 1932. Atuou como militante do partido na Bahia até 1936, quando foi enviado pela direção do partido para São Paulo. Após algumas prisões conseguiu se eleger deputado no ano de 1943. Depois de um período alvorotado de militância, após prisões e divergências políticas com o Partido Comunista do Brasil (PCB) Marighella foi expulso do partido no ano de 1967 (REIS FILHO, 1989).

Do ano de sua expulsão em diante, Marighella passou a se dedicar à militância armada, escrevendo, inclusive, textos que justificavam tal posição. Foi assim no ano de 1968, quando escreveu sobre a "guerrilha no Brasil", pontuando os aspectos latino-americanos postuladores de seu posicionamento, destacando o caso de Cuba como exemplo a ser seguido pelos países latinoamericanos.

O esforço de Marighella foi para que houvesse um novo instrumento de lutas que superasse a militância tradicional, que se expressava, via de regra, em partidos políticos. Nesse sentido, salientava que uma militância vanguardista não atrelada aos aparelhos do Estado era necessária pelo fato de ser mais prática e adequável às situações hostis com mais facilidade. Outro ponto que foi frisado pelo líder da ALN era que esse movimento, basicamente, se pautava pelas ações, sem se prender aos debates teóricos.

A ALN constituiu-se, numa organização combativa, focada na ação revolucionária, sendo, portanto, os debates teóricos tratados como desperdício de tempo. Toda a teoria, na concepção de Marighella, tinha sido expressa nos escritos do líder bolchevique, Lênin, na então recente revolução russa. Aos militantes comunistas, caberia a partir desse pressuposto focar-se em ações práticas e combativas (MARIGHELLA, 1979).

Soares (2002) defende que no que tange às estratégias e táticas, em seus documentos a ALN defendia que a luta armada deveria ocorrer em duas etapas, primeiramente nas cidades e, depois, no campo. Sendo assim, a guerrilha urbana se constituiria em uma fase de propaganda, treinamento de combatentes e arrecadação de recursos para uma futura guerrilha rural. Nas palavras de Soares: "A guerrilha no campo tornar-se-ia a fase decisiva 
e fundamental para, com o apoio da classe operária e camponesa, derrotar a ditadura militar e implementar um governo revolucionário de libertação nacional, que estabeleceria as medidas necessárias para criar as bases para o socialismo no Brasil" (SOARES, 2012, p. 30).

Denise Rollemberg (2001) sublinha que:

Como Cuba apoiava preferencialmente a ALN, as relações de Marighella com o governo cubano foram, em um certo sentido, mistificadas pela repressão e, até certo ponto, pela própria esquerda. Haveria uma certa subordinação do líder brasileiro às orientações dos cubanos. Provavelmente, a própria presença de Marighella na Conferência da OLAS e a preferência dos cubanos, por si só, levaram a esta suposição. Na verdade, segundo os depoimentos de militantes da ALN que passaram pelo treinamento e que tiveram contato com Marighella, a situação era outra. Apesar das relações com Cuba, Marighella teria uma visão da revolução bem diferente do modelo foquista. Seria um longo processo e dependia de uma complexa rede que apenas começava a ser tecida (ROLLEMBERG, 2001, p.41).

Marighella fazia a leitura do processo revolucionário a partir da realidade brasileira. Sua intenção era propor uma ruptura com o regime levando em conta a história e as peculiaridades do Brasil. Por isso seu movimento ganhou importância, uma vez que rompia com as determinações do PC soviético e não era uma simples reprodução do modelo cubano.

\section{Religião e militância como práxis libertária}

A certeza de que o projeto de libertação proposto por Marighella adstringia com preceitos cristãos era interpretado à luz do termo espiritualidade, que alguns cristãos libertários denominam de práxis cristã.

Nós cremos que há lugares onde a única maneira de dizer libertação - por exemplo - é fazê-la. E devemos crer que, de alguma maneira em todos os tempos e em todos os lugares, a única maneira de dizer é fazer (...).

Realizar-se, entre nós, passou a ser sinônimo de realizar-se na ação, na práxis de algumas obras concretizadas e transformadoras. Para nós a "realização pessoal" exige realização social. Nesse sentido, os personalismos subjetivistas e as fronteiras de classe, de estado, de status... nos fazem mal espiritualmente e fazem chiar a contextura interpessoal e práxica de vizinhança, país ou de mundo, que nossa inter-relacionalidade e nossa praxidade pedem (CASALDÁLIA; VIRGIL, 1993, p. 73).

Essa noção de espiritualidade já vigorava no seio dos setores progressistas cristãos e foi sistematizada pelo cristianismo de libertação ao longo dos anos. Tal mentalidade fazia com que houvesse cada vez 
mais sintonia entre cristãos e militantes políticos na busca pela liberdade democrática e pelo fim do regime militar.

Os movimentos dedicados à transformação social através da ação militante podem ser analisados sob o prisma da filosofia da práxis. Usualmente eles trazem consigo forte influencia teórica comprometida com a superação de determinados períodos históricos críticos - do ponto de vista social. Sua natureza liga-se à realidade histórica humana e se compromete com a superação dos entraves na busca pela instauração de uma nova realidade social (VÁZQUEZ, 1990).

Ao longo da história do pensamento filosófico, inúmeros pensadores se dedicaram em refletir sobre a práxis. Entretanto, destaca-se dentre eles os pensadores marxistas, simplesmente pelo fato de se empenharem em fazer da reflexão filosófica algo exequível no desafio de transformar a sociedade. É de Marx e Engels a célebre frase: "Os filósofos limitaram-se até agora em interpretar o mundo de diferentes modos; do que se trata é de transformá-lo" (MARX; ENGELS, 2005, p. 100). Tal frase expressa com bastante nitidez o intuito dos pensadores marxistas ao se debruçarem sobre a temática da práxis: viabilizar a mudança radical na sociedade.

Na obra Teses sobre Feuerbach, Marx e Engels encontraram a inspiração necessária para elaborar suas ideias sobre a práxis.

VI. Feuerbach dissolve a essência religiosa na essência humana. Mas a essência humana não é uma abstração inerente ao indivíduo singular. Em sua realidade, é o conjunto das relações sociais.

VIII. Toda a vida é essencialmente prática. Todos os ministérios que levam a teoria para o misticismo encontram solução racional na práxis humana e na compreensão dessa práxis (MARX; ENGELS, 2005, p. 11-12).

O que motivou Marx e Engels foram as afirmações de Feuerbach sobre a abstração, na qual a práxis só encontra "lugar em Deus" (VÁZQUEZ, 1990, p. 30). Na obra Essência do cristianismo, Feuerbach desenvolve sua tese de que o ser humano projeta as representações a partir de seu imaginário, afirmação esta que o levou a ser criticado por aqueles dois pensadores.

A "libertação" é um ato histórico e não um ato de pensamento, e é ocasionada por condições históricas, pelas con[dições] da indústria, do co[mércio], [da agricul]tura, do inter[câmbio][...].

A "concepção" feuerbachiana do mundo sensível limita-se, por um lado, à mera contemplação deste último, e por outro lado, à mera sensação; ele diz "o homem" em vez de os "homens históricos reais" (MARX; ENGELS, 2005, p. 29-30). 
Baseado em tais reflexões, Marx e Engels propõem a práxis a partir das condições materiais, isto é, pela revolução econômica e social. O pensamento marxista entende a práxis da pessoa humana como critério da verdade e sinaliza para tal práxis como o fundamento e fim de toda a teoria.

A concepção marxista de práxis pressupõe a releitura tanto do materialismo tradicional quanto do idealismo. Como faz uso da dialética, ela nega e absorve elementos tanto do primeiro quanto do segundo. Dessa forma, entende-se que ela extrapola a simples atividade da consciência humana, como afirmava Feuerbach, implicando na ação do ser humano, que participa da história com o intuito de transformá-la.

Leandro Konder destaca que, dentre os pensadores marxistas, Antônio Gramsci merece atenção especial. O italiano debruçou-se no estudo do marxismo a partir de uma concepção centrada na práxis. Konder defende que Gramsci foi o precursor em termos de elaboração das questões antropológicas em torno da temática.

Gramsci foi o primeiro a formular explicitamente a ideia de que concebido o homem como sujeito da práxis, não tem muito sentido perguntarmos: quem é o homem? O homem não é; seu ser consiste num tornar-se. O que nos cabe indagar, então, é o que o homem pode se tornar? (KONDER, 1992, p. 92).

Para Gramsci, a práxis consiste numa ação transformadora mediada pela reflexão crítica, isto é, não se limita à prática repetitiva. Ela consiste na ação objetiva de superação da realidade e que, por ser reflexiva, aponta novos horizontes e questões relacionadas ao cotidiano.

A ação transformadora da realidade torna-se possível à medida que o ser humano reflete sobre o cotidiano de suas ações. Nesse sentido, o "homem comum" encontra-se limitado em relação a ela pelo fato de estar cercado por mecanismos que obscurecem e limitam sua percepção de mundo. Como salienta Adolfo Vázquéz:

O homem comum e corrente é um ser social e histórico; ou seja, encontra-se imbricado numa rede de relações sociais e enraizado num determinado terreno histórico. Sua própria cotidianidade está condicionada histórica e socialmente, e o mesmo se pode dizer da visão que tem da própria atividade prática. Sua consciência nutre-se igualmente de aquisições de toda espécie: ideias, valores, juízos e preconceitos, etc. Nunca se enfrenta um fato puro; ele está integrado numa determinada perspectiva ideológica, porque ele mesmo - com sua cotidianidade histórica e socialmente condicionada - encontra-se em certa situação histórica e social que engendra essa perspectiva (VÁZQUEZ, 1990, p. 9). 
Por isso Gramsci chama a atenção para uma figura de grande importância na sociedade: "o intelectual orgânico". Tal indivíduo, além de manter o constante contato com o povo, é responsável por "organizar a classe que representa”, ou seja, viabilizar o conhecimento teórico e organizar as ações práticas para as transformações sociais (GRAMSCI, 1999, p. 25). Essa ação só é possível porque ele dedica parte de seu tempo na abstração e reflexão crítica da realidade. Nesse aspecto, o autor atenta para os intelectuais eclesiásticos, que consistem na categoria mais típica dos intelectuais orgânicos.

A mais típica dessas categorias intelectuais é a dos eclesiásticos, que monopolizaram durante muito tempo (numa inteira fase histórica, que é parcialmente caracterizada, aliás, por esse monopólio) alguns serviços importantes: a ideologia religiosa, isto é, a filosofia e a ciência da época, com a escola, a instrução, a moral, a justiça, a beneficiência, a assistência, etc. (GRAMSCI, 1999, p. 16).

As classes possuem intelectuais que as representam, tendo como principal área de concentração o campo da formação. A responsabilidade que lhes é incumbida compreende: educação, formação de uma nova cultura, organização de sua classe, participação das lutas cotidianas que envolvem sua classe.

Nesse sentido, tanto a ALN quanto o cristianismo de libertação possuem em seu eixo de ação a perspectiva da práxis transformadora, comprometida em sua análise, com superação dos entraves sociais pela via revolucionária, opondo-se as formas de dominação e políticas que inviabilizam o projeto de emancipação social.

\section{Conclusão}

A realidade opressora ditatorial dos anos 1960 e 1970, instalada na América Latina após o triunfo da Revolução Cubana, fez com que os movimentos de contestação do status quo, fossem combatidos e perseguidos sob a condição de inimigos da ordem social vigente. Tal posição contribuiu para que confluíssem para um movimento unívoco na luta contra a exploração social e a submissão imposta aos países latino-americanos. Com isso, os setores da Igreja Católica que já vinham refletindo sobre a participação na política, acabaram por ser impelidos à reivindicação social, juntamente com os demais movimentos - armados inclusive.

A confluência entre a militância e a espiritualidade ocorre justamente por sua incidência prática sobre a realidade. A libertação proposta tanto por um quanto por outro se dão no seio da história, ou seja, o inimigo comum a ser superado sendo histórico precisa ser superado através da concretude da práxis. 
A reflexão que se faz em torno da práxis filosófica justifica a utilização de elementos como militância política e espiritualidade para que vislumbre horizontes utópicos semelhantes descritos sob diferentes formas. Enquanto o cristianismo entende a liberdade utópica sob a expressão "Reino de Deus", o comunismo a entende como "Reino da Liberdade". Em comum, a esperança de que os valores de igualdade e liberdade sejam vividos de forma plena e responsável e que a injustiça e exploração sejam extirpadas completamente.

O exemplo dado pelo cristianismo de libertação rompe com o velho axioma de que a religião é alienadora. A religião pode ser entendida como um significante vazio, que depende do significado que lhe é conferida para poder ser qualificada. Ela pode ser alienante e pode ser libertária, assim como a política. Tudo depende do significado empregado.

No caso dos dominicanos e Marighella, a confluência se deu em torno do horizonte da libertação e o anseio pela liberdade democrática que foi suprimida pelo golpe militar de 1964, sendo aprofundada por meio dos atos institucionais.

\section{Referências bibliográficas}

BETTO, Frei. Batismo de Sangue: os dominicanos e a morte de Carlos Marighella. Rio de Janeiro: Civilização Brasileira, 1982.

BORGES, Nilson. A Doutrina de Segurança Nacional e os governos militares. In: FERREIRA, Jorge; NEVES DELGADO, Lucilia de Almeida (orgs.). O tempo da ditadura: regime militar e movimentos sociais em fins do século XX. Rio de Janeiro: Civilização Brasileira, 2007.

CASALDÁLIGA, Pedro; VIRGIL, José Maria. Espiritualidade da Libertação. Petrópolis: Vozes, 1993.

DREIFUSS, René Armand. 1964. A conquista do Estado: ação política, poder e golpe de classe. Petrópolis: Vozes, 1981

DUSSEL, Enrique. Teologia da Libertação: um panorama desde seu desenvolvimento.

Petrópolis: Vozes, 1999.

GRAMSCI, Antônio. Cadernos do cárcere. Vol. 1. Rio de Janeiro: Civilização Brasileira, 1999. HINKELAMMERT, Franz J. Critica a la razón utopica. San José: DEI, 1984.

JOSÉ, Emiliano. Carlos Marighella: o inimigo número um da ditadura militar. São Paulo: Casa Amarela, 2004.

KONDER, Leandro. O Futuro da filosofia da práxis: pensamento de Marx no século XXI. Rio de Janeiro: Paz e Terra, 1992.

LÖWY, Michael. A guerra dos deuses: religião e política na América Latina. Petrópolis: Vozes, 2000 . 
MARIGHELLA, Carlos. Escritos de Carlos Marighella. São Paulo: Editorial Livramento, 1979. MARX, Karl; ENGELS, Friedrich. Manifesto do Partido Comunista. São Paulo. Martin Claret, 2005.

REIS FILHO, Daniel Aarão. A revolução faltou ao encontro: os comunistas no Brasil. São Paulo: Brasiliense, 1989.

RIBEIRO, Cláudio de Oliveira. A teologia da libertação morreu?: reino de Deus e espiritualidade hoje. São Paulo: Fonte Editorial, 2010.

ROLLEMBERG, Denise. A ALN e Cuba: apoio e conflito. Cadernos AEL, Campinas, v. 8, n. 14/15, p. 205-255, 2001.

VÁZQUÉZ, Adolfo Sánchez. Filosofia da práxis. São Paulo: Paz e Terra, 1990.

Submetido em: 12-8-2020

Aceito em: 28-9-2020 
